\title{
Substance abuse and dependence among patients attending an emergency hospital in eastern Nile delta, Egypt
}

\author{
Mostafa Amr' ${ }^{1}$, Abdel-Hady El-Gilany², Ahmed El-Mogy ${ }^{1}$, Warda Fathi ${ }^{1}$ \\ Department of Psychiatry, Mansoura University, Egypt
}

\begin{abstract}
Background: Substance abuse and dependence are frequently encountered in emergency hospitals. The aims of this study were to estimate the prevalence of drug abuse and dependence among patients attending Emergency Hospitals and to describe the sociodemographic, clinical and psychiatric features of these patients .Secondary aims were to evaluate the type of medical care given to these patients and to assess the predictors of substance abuse and dependence Methods: All 1,526 patients attending the Mansoura emergency hospital during the month of April 2012 were included in this study. Alcohol and illicit drug use were assessed using a questionnaire filled in by the patients and their relatives followed by an interview based on the Arabic version of Mini international neuropsychiatric interview (MINI) for the diagnosis of comorbid psychiatric disorders.

Results: After exclusion of 155 cases, 1,317 patients were included: $108(8 \%)$ with substance abuse and $47(3.5 \%)$ with substance dependence. Cannabis was the most common drug abused for $3.6 \%$ of patients followed by tramadol and polysubstance in $1.8 \%, 1.7 \%$ of patients respectively, whereas, tramadol ranked the first in the dependence group in $1.2 \%$ of patients followed by the cannabi and stimulants in $1 \%$ and $0.5 \%$ of patients respectively). Multivariate regression analysis showed that being of younger age $(<30$ years) (Odds ratio $O R=1.74)$, male and single with unsatisfactory income $(O R=3.71$, 1.59 and 2.66 respectively) and diagnosed with psychiatric illness $\mathrm{OR}=2.08$ ) positively predict the abuse status included. Those with status of drug dependence had features similar to the status of abuse patients except regarding reason for hospital referral and the presence of psychiatric illness. Conclusion: About one in ten of the attendants presented with either substance abuse or dependence. This should be considered during history taking and clinical examination of patients referred to an emergency hospital particularly in male gender, single, younger age group with unsatisfactory income.
\end{abstract}

Keywords: Substance abuse; dependence; emergency hospital; Egypt

Received date: 2 -12-2013

Accepted date: $30-01-2014$

doi: http://dx.doi.org/10.4172/Psychiatry. 1000110

\section{Introduction}

Substance Use Disorders (SUD) are considered to be prevalent in emergency services (general emergency rooms -GER). Approximately 374000 patients aged over 12 were admitted in emergency services due to SUD in the United States in 2008 , which represents $8.5 \%$ of all SUDrelated interventions in that country in that year. ${ }^{1}$

Traditionally, the profile of the user visiting the ED is a male under the age of 30 , with polyconsumption of other drugs of abuse, who increases this use significantly at the weekends and nighttime. The most extensive use of alcohol, the incorporation of the female, and the greater introduction of consumption as an instrument of entertainment have probably made the day and time the patients turn up more random after 10 years. ${ }^{2}$ Study at Tihar jail in India (2001) among 6800 male drug abusers found that commonest age group was 21-25 years; $50 \%$ were illiterates; $44 \%$ were unmarried; $8 \%$ were unemployed. ${ }^{3}$ Moreover, Sau et al. (2013) found that $10.2 \%$ of drug abusers were illiterates; $40.8 \%$ were unmarried; $10.9 \%$ were unemployed; $34.15 \%$ cases had unsatisfactory income. ${ }^{4}$

Correspondence

Mostafa Amr

Professor of Psychiatry

Mansoura University, Egypt,

Email: mostafapsy@yahoo.com
Mental health and substance abuse practitioners and researchers have become increasingly conscious of a link between substance use and mental disorders in recent years. ${ }^{5}$ Approximately 50 percent of persons with a substance use disorder have had a co-occurring mental disorder in their lifetime. ${ }^{6}$

In Middle Eastern Arab countries, particularly Egypt, there is scarce information on the problem of patients with substance abuse or dependence attending emergency rooms in general hospitals. Abou Eleinen $(2008)^{7}$ conducted a study on 150 patients presenting with drug overdose attending Mansoura Emergency Hospital over the period of 2002-2004. The most common detected substance in urine was cannabis $(68 \%)$, followed by opiates $(42.7 \%)$, and then barbiturates $(26.7 \%)$. The diagnosis of polysubstance use was more prevalent than single substance use. All but one of the patients gave a clear history of regular cannabis (bango) use.

Results from emergency room studies differ between studies and between countries.8 Comparative findings on the association between alcohol and casualties across countries and cultures appear to reflect usual drinking patterns within the countries concerned ${ }^{8}$, therefore, information from different countries is needed. Egypt lacks complete data on alcohol and illicit drug use among emergency room patients.

The positive identification of patients under the 
influence of alcohol and illicit drugs in the emergency room is necessary for appropriate treatment and to develop suitable intervention programmes. Outside Egypt, brief counseling interventions for alcohol and illicit drug abuse use have proven effective. ${ }^{9}$ However, before developing such intervention programmes in Egypt, more data are required on whether these interventions should be region specific.

The aims of this study were to estimate the prevalence of drug abuse and dependence among patients attending Emergency Hospitals and to describe the sociodemographic, clinical, psychiatric features of these patients. Secondary aims were to evaluate the type of medical care given to these patients and to assess the predictors of substance abuse and dependence.

\section{Method}

This is a cross sectional study done in Mansoura University Emergency Hospital, Egypt. The Mansoura University emergency hospital was founded in 1991. It provides services in different medical fields for many Egyptian governorates as (Dakahlia, Port Said, Damietta, Gharbia and Kafr Elshik) .According to statistics of the hospital, the year before the study (2010-2011), the total number of attending patients was 125126. All cases visited the hospital during a period of one month (from 1 April to 30 April 2012) were included in the study. A pilot study on 200 patients revealed that $13.5 \%$ of them reported either abuse or dependence. With the worst acceptable prevalence of $11 \%$, alpha error of $5 \%$ and study power of $80 \%$, the expected sample size is 1090 at least. Instruction on the study procedures was given to the emergency room and research staff by the main researcher. The researchers made site visits to check these procedures. A three consultant psychiatrists interviewed patients or their relatives either in emergency room or observation rooms to complete the questionnaire.

\section{Study questionnaire}

A patient questionnaire was used in order to obtain more detailed information about the patient's substance use. 10 The questionnaire contained a number of demographic data including age, gender, education; occupational and marital situation. Reason for visit was either injury or illness, whereas type of visit included traffic accident, accident, violence and physical and history of psychiatric illness. Referral could be by ambulance, own initiative, or health care personnel. It also includes inquiry about illicit drug use during the previous year: e.g., the use of hashish, bhang, amphetamine, benzodiazepines, heroin, cocaine, hallucinogenic, alcohol and anticholinergic medicines.

The questionnaire was followed by an interview by the psychiatry personnel based on the Arabic version of Mini international neuropsychiatric interview (MINI) ${ }^{11}$ for the diagnosis of co morbid psychiatric disorders. It also included sections of alcoholic abuse and dependence and non- alcoholic psychoactive substance abuse and dependence that were based on DSM-IV criteria ${ }^{12}$ to categorize the problem of substance use as dependence or abuse. The study was approved by the hospital authority and all patients participated gave a written consent before they were included in the study.

\section{Data analysis}

The prevalence rate of abuse and dependence among patients were calculated. Then the group of neither abuse nor addict was considered as a control group and was compared with each group of abuse or dependence separately. Data was analyzed using SPSS version 16. Age is presented as mean and SD. Unpaired student's t-test was used for group comparison. Qualitative variables were presented as number and per cent. Chi square was used to test the significance difference between groups. Multivariate logistic regression analysis models were generated between abuse and dependence (the dependent variables) and patient's demographic and clinical characteristics (independent variables) that proved significant at the univariate analysis. Odds ratio with $95 \%$ confidence were estimated, $\mathrm{p}$ value < 0.05 was considered significant.

\section{Results}

The initial number of patients examined was 1526 (patients admitted to the emergency hospital). We excluded 92 with severe injuries, 63 with severe medical illnesses, leaving 1371 patients of which 181 (11.8\%) were case positive on self report examination. Of these only $155(10.1 \%)$ were verified after the MINI interview by the psychiatric personnel. The 26 excluded were added to the control group.

Among patients with substance abuse, cannabis ranked first $(3.6 \%)$ then tramadol $1.8 \%$, polysubstancel.7\%, followed by stimulants group (1.3\%), alcohol (1.1\%), and finally anticholinergics $(0.5 \%)$ and volatile substances $(0.3 \%)$ (Table 1$)$. In dependence group, tramadol ranked first $(1.2 \%)$ followed by the cannabis $(1 \%)$ and stimulants $(0.5 \%)$, heroin $(0.37 \%)$, anticholinergics, polysubstance $(0.22 \%)$ and alcohol and volatile substances $(0.07 \%$ each). Urine toxicology shows that $30 \%$ used at least one of these illicit drugs: 20 patients (20\%) tested positive for cannabis, $6(6 \%)$ had a positive urine screen for amphetamine, and 10 patients $(10 \%)$ tested positive for opiates.

Table 2 showed preponderance of abuse among single, younger males, who had lower education and unsatisfactory income (each $\mathrm{P}=\leq 0.001$ ), whereas dependence was predominantly among single, younger, unemployed male, who had unsatisfactory income (each $\mathrm{P}=\leq 0.001$ ).

Table 3 showed that anxiety disorders particularly generalized anxiety disorder were more prevalent in abuse group followed by the somatoform and mood disorders $(60.7 \%, 13.1 \% .13 .1 \%)$ whereas the mood disorders and schizophrenia (25\% each) were more encountered in the dependence group. substance Intoxication were higher in the abuse than the dependence group with only three cases of heroin withdrawal were recorded in the dependence group.

Table 4 showed the top three frequent medical services in abuse group were intensive care $(28.7 \%)$, observation room $(21.3 \%)$ and medical ward $(14.8 \%)$ whereas the top three frequent medical services in dependence group were medical ward (29.8\%), psychiatric ward (23.4\%) and intensive care $(17 \%)$.

Table 5 illustrates the generated multivariate regression analysis models, significant correlates that positively predict the abuse status included being of younger age (< 30 years) (Odds ratio $O R=1.74$ ), being male and single, with unsatisfactory income $(\mathrm{OR}=3.71,1.59$ and 2.66 respectively), with accidents as the main reason for referral to hospital $(O R=2.15)$ ) and diagnosed with psychiatric illness $O R=2.08)$. Those with status of drug dependence depicts that similar to the stat of abuse socio-demographics including age, gender 


\begin{tabular}{|c|c|c|}
\hline & Abuse & \\
\hline$N(\%)$ & Dependence & \\
\hline \multicolumn{3}{|l|}{$\mathrm{N}(\%)$} \\
\hline Overall & $108(8.0 \%)$ & $47(3.5 \%)$ \\
\hline \multicolumn{3}{|c|}{ Psychoactive substances } \\
\hline Alcohol & $15(1.1 \%)$ & $1(0.07 \%)$ \\
\hline Cannabis & $48(3.6 \%)$ & $14(1.04 \%)$ \\
\hline Stimulants & $18(1.3 \%)$ & $7(0.5 \%)$ \\
\hline Heroin & - & $5(0.37 \%)$ \\
\hline Tramadol & $24(1.8 \%)$ & $16(1.2 \%)$ \\
\hline Volatile substances & $4(0.3 \%)$ & $1(0.07 \%)$ \\
\hline Anticholinergics & $7(0.5 \%)$ & $3(0.22 \%)$ \\
\hline Polysubstance & $23(1.7 \%)$ & $3(0.22 \%)$ \\
\hline
\end{tabular}

\begin{tabular}{|c|c|c|c|c|c|}
\hline & Control (1190) N (\%) & Abuse (108) N (\%) & Significance & Dependence (47) N (\%) & Significance \\
\hline Age (Mean \pm SD) & $42.5 \pm 6.9$ & $34.2 \pm 5.2$ & $t=12.2, P \leq 0.001$ & $35.7 \pm 4.8$ & $t=6.7, P \leq 0.001$ \\
\hline \multicolumn{6}{|l|}{ Sex } \\
\hline Male & $580(48.7)$ & $90(83.3)$ & $x^{2}=47.5$ & $36(76.6)$ & $x^{2}=14.0$ \\
\hline Female & $610(51.3)$ & $18(16.7)$ & $P \leq 0.001$ & $11(23.4)$ & $P \leq 0.001$ \\
\hline \multicolumn{6}{|l|}{ Education } \\
\hline Below secondary & $813(68.3)$ & 93(86.1) & $x^{2}=14.9$ & $37(78.7)$ & $x^{2}=2.3$ \\
\hline Secondary and above & $377(31.7)$ & $15(13.9)$ & $P \leq 0.001$ & $10(21.3)$ & $P=0.13$ \\
\hline \multicolumn{6}{|l|}{ Occupation } \\
\hline Employed & $490(41.2)$ & $52(48.1)$ & $x^{2}=2.8$ & $6(12.8)$ & $x^{2}=15.2$ \\
\hline Non-employed & $700(58.8)$ & $56(51.9)$ & $P=0.1$ & $41(87.2)$ & $P \leq 0.001$ \\
\hline \multicolumn{6}{|l|}{ Residence } \\
\hline Urban & $950(79.8)$ & $88(81.5)$ & $x^{2}=0.2$ & $39(83.0)$ & $x^{2}=0.3$ \\
\hline Rural & $240(20.2)$ & $20(18.5$ & $\mathrm{P}=0.7$ & $8(17)$ & $P=0.6$ \\
\hline \multicolumn{6}{|l|}{ Marital status } \\
\hline Single/divorced/widow & $368(30.9)$ & $58(53.7)$ & $x^{2}=16.2$ & $32(68.1)$ & $x^{2}=28.5$ \\
\hline Married & $822(69.1)$ & $50(46.3)$ & $P \leq 0.001$ & $15(31.9)$ & $P \leq 0.001$ \\
\hline \multicolumn{6}{|l|}{ Income } \\
\hline Satisfactory* & $175(14.7)$ & $40(37.0)$ & $x^{2}=35.7$ & $36(76.6)$ & $X^{2}=122.4$ \\
\hline Unsatisfactory & $1015(85.3)$ & $68(63.0)$ & $P \leq 0.001$ & $11(23.4)$ & $P \leq 0.001$ \\
\hline
\end{tabular}

*Satisfactory incomes means sufficient enough to satisfy living needs of the family (e.g., accommodation, food, transportation, clothes, costs of education for children and health) without any in-dept.

and being single with unsatisfactory income were positively correlated while of a psychiatric illness did not significantly predict the drug dependence status.

\section{Discussion}

In a developing country like Egypt there is a lack of information regarding the prevalence of patients with substance abuse or dependence looking for medical help at an emergency room. Most of the studies collected information on alcohol and substance use from general psychiatric clinics, in-patients at dedicated drug and alcohol dependency units], community studies ${ }^{13,14}$ and few studies from emergency room populations that depend mainly on toxicological analysis using drug and blood screening for psychoactive substances with lack of valid psychometric tool for the clinical assessment of the cases. ${ }^{7}$

Calle (2006) ${ }^{15}$ in a survey of medical notes of 1914 Belgian patients attending the emergency department in a university hospital reported that $10 \%$ of patients were diagnosed with substance abuse leading to emergency department admission. Vitale in Netherlands (2006) ${ }^{11}$ found that data on alcohol and illicit drug abuse (self reported and staff judgment combined) resulted in prevalence rates of $4.9 \%-18.2 \%$ and $1.4-10.1 \%$

In our study the prevalence of substance abuse and dependence was $8 \%$ and $3.5 \%$ respectively which was similar to the western studies but is much lower than the community surveys in Egypt. These results could be inaccurate: The possibility of individuals feeling uncomfortable about admitting alcohol or drug use may result in reduced prevalence rates due to inhibited disclosure16. Similarly moral , cultural, societal , and legal constraints on individuals with regard to alcohol and drug use may deter some individuals from presenting for treatment and thus prevalence rates from medical institutions may not fully representative of the problem. ${ }^{17}$

In light of the results obtained through the study, the cannabis was the frequent one used in both abused and 


\begin{tabular}{|c|c|c|c|}
\hline & Control(107) N(\%) & Abuse (17) N(\%) & Dependence (4) N(\%) \\
\hline Anxiety disorders: & $65(60.7)$ & $3(17.6)$ & $1(25.0)$ \\
\hline GAD & $44(41.1)$ & $1(5.9)$ & - \\
\hline OCD & $1(0.9)$ & - & - \\
\hline PTDS & $2(1.9)$ & - & - \\
\hline Panic & 18(16.8) & $1(5.9)$ & $1(25.0)$ \\
\hline Phobic & - & $1(5.9)$ & - \\
\hline Somatoform disorders: & $14(13.1)$ & - & - \\
\hline Somatization & $5(4.7)$ & & \\
\hline Conversion & $9(8.4)$ & & \\
\hline Dissociative disorders (Amnesia) & $9(8.4)$ & - & - \\
\hline Organic mental disorders: & $3(2.8)$ & & \\
\hline Dementia & $2(1.9)$ & & \\
\hline Delirium & $1(0.9)$ & & \\
\hline Schizophrenia & 12(11.2) & $3(17.6)$ & $2(50.0)$ \\
\hline Mood disorders: & $14(13.1)$ & $13(76.5)$ & $2(50.0)$ \\
\hline Manic episode & $8(7.5)$ & $8(47.1)$ & $1(25.0)$ \\
\hline Depressive episode & $6(5.6)$ & $5(29.4)$ & $1(25.0)$ \\
\hline Intoxication: & - & 11(64.7) & $2(50.0)$ \\
\hline Alcohol & & $4(23.5)$ & $1(25.0)$ \\
\hline Hashish & & $2(11.8)$ & - \\
\hline Amphetamine & & $1(5.9)$ & - \\
\hline Anxiolytics & & $3(17.6)$ & $1(25.0)$ \\
\hline Tramadol & & $1(5.9)$ & \\
\hline \multirow[t]{2}{*}{ Withdrawal (Heroine) } & - & - & $3(75.0)$ \\
\hline & Control(107) N(\%) & Abuse (17) N(\%) & Dependence (4) N(\%) \\
\hline Anxiety disorders: & $65(60.7)$ & $3(17.6)$ & $1(25.0)$ \\
\hline GAD & $44(41.1)$ & $1(5.9)$ & - \\
\hline OCD & $1(0.9)$ & - & - \\
\hline PTDS & $2(1.9)$ & - & - \\
\hline Panic & $18(16.8)$ & 1(5.9) & $1(25.0)$ \\
\hline Phobic & - & $1(5.9)$ & - \\
\hline Somatoform disorders: & $14(13.1)$ & - & - \\
\hline Somatization & $5(4.7)$ & & \\
\hline Conversion & $9(8.4)$ & & \\
\hline Dissociative disorders (Amnesia) & $9(8.4)$ & - & - \\
\hline Organic mental disorders: & $3(2.8)$ & - & - \\
\hline Dementia & $2(1.9)$ & & \\
\hline Delirium & $1(0.9)$ & & \\
\hline Schizophrenia & $12(11.2)$ & $3(17.6)$ & $2(50.0)$ \\
\hline Mood disorders: & $14(13.1)$ & $13(76.5)$ & $2(50.0)$ \\
\hline Manic episode & $8(7.5)$ & $8(47.1)$ & $1(25.0)$ \\
\hline Depressive episode & $6(5.6)$ & $5(29.4)$ & $1(25.0)$ \\
\hline Intoxication: & - & $11(64.7)$ & $2(50.0)$ \\
\hline Alcohol & & $4(23.5)$ & $1(25.0)$ \\
\hline Hashish & & $2(11.8)$ & - \\
\hline Amphetamine & & $1(5.9)$ & - \\
\hline Anxiolytics & & $3(17.6)$ & $1(25.0)$ \\
\hline Tramadol & & $1(5.9)$ & \\
\hline Withdrawal (Heroine) & - & - & $3(75.0)$ \\
\hline
\end{tabular}

dependence groups. The same finding was reported by ${ }^{7,14}$ who found that cannabis family was common in our locality, as it is relatively of low price, can be easily obtained and cultivated illegally in many areas in Egypt Similarly, Bonomo and Proimos (2005) ${ }^{18}$ found that cannabis is the most common substance of abuse. Its use usually starts at about 16-17 years old. In addition, $67 \%$ of young men aged 18-30 years use marijuana on a regular basis in Emergency department injured patients. ${ }^{19}$ 
Table 4: Data on the type of medical care after evaluation in the emergency department in normal, abuse and dependence groups (all in percent)

\begin{tabular}{|c|c|c|c|} 
& Control (N= 1190) & Abuse(N= 108) & Dependence(N= 47) \\
\hline Intensive care & $498(41.8 \%)$ & $31(28.7 \%)$ & $8(17.0 \%)$ \\
\hline Medical Ward & $131(11.0 \%)$ & $16(14.8 \%)$ & $14(29.8 \%)$ \\
\hline Psychiatric ward & $36(3.0 \%)$ & $14(13.0 \%)$ & $11(23.4 \%)$ \\
\hline Observation room & $107(9.0 \%)$ & $23(21.3 \%)$ & $6(12.8 \%)$ \\
\hline Left hospital against advice & $36(3.0 \%)$ & $12(11.1 \%)$ & $2(4.3 \%)$ \\
\hline Ambulatory care & $311(26.1 \%)$ & $9(8.3 \%)$ & $4(8.5 \%)$ \\
\hline Deceased on Arrival & $71(6.0 \%)$ & $3(2.8 \%)$ & $1(2.1 \%)$ \\
\hline
\end{tabular}

Table 5: Multivariate regression models of abuse and dependence among patients attending Mansoura University Emergency Hospital in relation to independent socio-demographic and clinical correlates

\begin{tabular}{|c|c|c|c|c|}
\hline \multirow[t]{2}{*}{ Independent variables } & \multicolumn{4}{|c|}{ Multivariate regression models: Odds ratio (95\% Confidence intervals) } \\
\hline & Abuse $^{a}$ & $P$ value & Dependence $^{b}$ & $P$ value \\
\hline \multicolumn{5}{|l|}{ - Age groups: } \\
\hline$<30$ years & $1.74(1.25-2.41)$ & 0.001 & $1.53(1.09-2.15)$ & 0.034 \\
\hline$\geq 30$ years & Reference & & Reference & \\
\hline \multicolumn{5}{|l|}{ - Gender: } \\
\hline Males & $3.71(2.08-6.63)$ & 0.001 & $1.91(1.31-2.77)$ & 0.007 \\
\hline Females & Reference & & Reference & \\
\hline \multicolumn{5}{|l|}{ - Marital status: } \\
\hline Single & $1.59(1.15-2.21)$ & 0.003 & $1.96(1.54-2.49)$ & 0.006 \\
\hline Married & Reference & & Reference & \\
\hline \multicolumn{5}{|l|}{ - Income: } \\
\hline Unsatisfactory & $2.66(1.72-4.15)$ & 0.001 & $1.96(1.54-2.49)$ & 0.008 \\
\hline Satisfactory & Reference & & Reference & \\
\hline \multicolumn{5}{|l|}{-} \\
\hline - Psychiatric illness & $2.08(1.61-2.67)$ & & & \\
\hline Present & Reference & & $1.16(0.72-1.86)$ & \\
\hline Absent & & 0.009 & Reference & 0.271 \\
\hline
\end{tabular}

${ }^{\mathrm{a} F o r}$ Abuse model: Percent predicted for the multivariate regression model $=75.8$, Homser and Lemeshow Chi square $=4.539, P=0.602 . b$ For dependence model: Percent predicted for multivariate regression model= 71.2 , Homser and Lemeshow Chi square $=6.012, P=0.109$.

Multivariate regression analysis revealed that being younger, unmarried, male sex and unsatisfactory income were significant risk factors of substance abuse and dependence among an emergency university hospital.These findings partially coincide with those of another Egyptian study carried out on 457 patients of drug dependence; the majority of the studied addicts were males (70.0\%), from urban areas $(75.7 \%)$, current smokers $(95.6 \%)$, not married (single, divorced, and widowed) (70.0\%), aged 20-40 years (81.4\%), and of low educational level. ${ }^{20}$ Moreover, in another study it was re 7 vealed that substance abuse was more common among males and unmarried or separated individuals. $^{21}$

Individuals with co-occurring substance use and mental disorders often are more difficult to treat and experience worse outcomes than other patients. ${ }^{22}$ Persons with these co-occurring disorders also have higher rates of emergency department (ED) use than those with mental disorders alone. ${ }^{23}$ Identifying those individuals with co-occurring disorders and the problems they experience is essential to developing appropriate treatment strategies at all points of contact, including the ED visit.This may partially support our findings of higher psychiatric comorbidity observed among the substance abusers.

With regard to our figures, four major limitations are to be considered. First; the study period was limited to one month. Second, this is a single center hospital based study in small sample of patients seeking emergency care and its results are not reflecting the situation in the community. Third , toxicological screening was not performed routinely and we had no access to the police files on traffic accidents and fights, Fourth, there are not clear cut definitions for some of the items under investigation (e.g., need for psychiatric referral , causal relationship between the substance related disorder and ED visits.

\section{Conclusion}

About one in ten of the attendants presented with either substance abuse or dependence. This should be considered during history taking and clinical examination of patients referred to an emergency hospital particularly in male gender, single, younger age group with unsatisfactory income.

\section{Financial or other competing interests} None

\section{References}

1. Rockville MD. Substance Abuse and Mental Health Services Administration. Results from the 2008 National Survey on Drug Use and Health: National Findings (Office 
of Applied Studies, NSDUH Series H-36, HHS Publication No. SMA 09-4434, 2009.

2. Cherpitel CJ, Ye Y. "Drug use and problem drinking associated with primary care and emergency room utilization in the US general population: data from the 2005 national alcohol survey," Drug and Alcohol Dependence, 2008 ; 97:226-230.

3. Ray R. Drug abuse among prison population. Ministry of Social Justice and Empowerment Govt. of India, and United Nations International Drug Control Programme, June 2002.

4. Sau M, Mukherjee A, Manna N, Sanyal S. Sociodemographic and substance use correlates of repeated relapse among patients presenting for relapse treatment at an addiction treatment center in Kolkata, India. African Health Sciences 2013; 13: 791 - 799 .

5. Morojele NK, Saban A, Seedat S. Clinical presentations and diagnostic issues in dual diagnosis disorders. Curr Opin Psychiatry, 2012; 25: 181-6.

6. Kessler R C, Nelson CB, McGonagle KA, Edlund MJ, Frank $R G$, et al.The epidemiology of co-occurring addictive and mental disorders: Implications for prevention and service utilization. American Journal of Orthopsychiatry, 1996; 66: 17-31.

7. Abou Eleinen, R, Mostafa M, Ghanem A, Elnaggar E, Elbayomy A. Psychoactive Drug Use in Toxicology Unit Patients, Mansoura Emergency Hospital, Egypt. NIDA international program, 2008.

8. Cherpitel CJ. Alcohol and violence-related injuries: an emergency room study. Addiction, 1993; 88: 79-88.

9. Woolard R, Nirenberg TD, Becker B, Longabaugh R, Minugh $P A$, et al. Marijuana use and prior injury among injured problem drinkers. Acad Emerg Med 2003; 10: 43-51.

10. Vitale SG, Van De Mheen D, Van De Wiel A, Garretsen HF. Alcohol and illicit drug use among emergency room patients in the Netherlands. Alcohol Alcohol, 2006; 41: 553-9.

11. Sadek A. Mini international neuropsychiatric interview (MINI): the Arabic translation. Cairo, Psychiatry Update, Institute of Psychiatry, 2000.

12. American Psychiatric Association. Diagnostic and Statistical Manual of Mental Disorders. 4th ed. (DSM-IV). Washington DC:American Psychiatric Press, 1994; 416-417.
13. Khalil,A, Okasha, T, Shawky M, Haroon A, Elhabiby M, et al. Characterization of Substance Abuse Patients Presenting for Treatment at a University Psychiatric Hospital in Cairo, Egypt.Addictive Disorders \& Their Treatment, 2008; 7: 199 -209 .

14. Hamdi E, Gawad T, Khoweiled A, Sidrak AE, Amer D, Mamdouh $R$, et al. Lifetime prevalence of alcohol and substance use in Egypt: a community survey. Subst Abus. 2013; 34: 97-104.

15. Calle PA, Damen J, De Paepe P, Monsieurs KG, Buylaert $W A$. A survey on alcohol and illicit drug abuse among emergency department patients. Acta Clin Belg. 2006; 61: 188-95.

16. Abou-Saleh MT, Ghubash R, Daradkeh TK. Al Ain Community Psychiatric Survey. I. Prevalence and sociodemographic correlates. Soc Psychiatry Psychiatr Epidemiol. 2001 36: 20-8.

17. Osman A, Shawoosh M. Heroin addiction in Saudi Arabia-not merely a behavioural problem. Ann Saudi Med. 2003; 23: 419-21.

18. Bonomo Y, Proimos J. Substance misuse: alcohol, tobacco, inhalants, and other drugs. BMJ. 2005; 330: 777-80.

19. Rich JA, Grey CM. Pathways to recurrent trauma amongyoung black men: traumatic stress, substance use and the code of the street". Am. J. Public Health 2005; 95: 816-824.

20. El-Sawy H, Abdel Hay M, Badawy A. Gender differences in risks and pattern of drug abuse in Egypt. Egypt J Psychiat Neurosurg 2010; 47: 413-8.

21. Merline AC, O'Malley PM, Schulenberg JE, Bachman JG, Johnston LD. Substance use among adults 35 years of age: prevalence, adulthood predictors, and impact of adolescent substance use. Am J Public Health. 2004; 94 : 96-102.

22. O'Brien CP, Charney DS, Lewis L, Cornish JW, Post RM, et al. Priority actions to improve the care of persons with cooccurring substance abuse and other mental disorders: $A$ call to action. Biol Psychiatry. 2004; 56: 703-13.

23. Curran GM, Sullivan G,Williams DK, Han X, Collins K, KeysJ, Kotrla KL.Emergency room use of persons with comorbid Psychiatric and substance abuse disorders. Ann Emerg Med. 2003: 41, 659-667. 